\title{
Decision-makers' attitudes toward the use of care robots in welfare services
}

\author{
Outi Tuisku $^{1} \cdot$ Satu Pekkarinen ${ }^{2} \cdot$ Lea Hennala ${ }^{2} \cdot$ Helinä Melkas $^{2}$
}

Received: 18 June 2021 / Accepted: 24 January 2022

(c) The Author(s) 2022

\begin{abstract}
The purpose of this study was to investigate the attitudes of decision-makers toward the use of care robots in welfare services. We investigated their knowledge regarding the use of care robots in welfare services as well as their attitudes toward using robots in their own care and in the care of various user groups, for example, children, youths, and older people. We conducted an online survey with a range of Finnish decision-makers as respondents $(N=176)$. The respondents were divided into two groups: service actors $(n=104)$ and research and development $(\mathrm{R} \& \mathrm{D})$ actors $(n=72)$. The respondents did not regard themselves as having much knowledge about robotics; however, the results showed that the R\&D actors had more overall knowledge of the use of robots than the service actors. The R\&D actors were found to be more willing to accept a robot as part of their own care as well as part of the care for various user groups. The contribution of this study is a better understanding of the views of the decision-makers who are or will be in charge of the acquisition of technological devices in welfare services.
\end{abstract}

Keywords Care robots $\cdot$ Robot acceptance $\cdot$ Human-robot interaction $\cdot$ HRI $\cdot$ Decision-makers $\cdot$ Welfare services

\section{Introduction}

Technology such as care robots has been pictured as one solution to the growing shortage of care workers in welfare services, for example, in the care of the elderly (Maibaum et al. 2021; Pirhonen et al. 2019). For example, care robots can be used to assist clients and their caregivers in their daily tasks, to monitor behaviors and health, and to provide companionship (Sharkey and Sharkey 2010). There are two main attitudes toward the use of robots in welfare services: high hopes that personalized health care will benefit from the use

Satu Pekkarinen

satu.pekkarinen@lut.fi

Outi Tuisku

outi.tuisku@tuni.fi

Lea Hennala

lea.hennala@lut.fi

Helinä Melkas

helina.melkas@lut.fi

1 School of Industrial Engineering, Tampere University of Applied Sciences, Tampere, Finland

2 School of Engineering Science, Lappeenranta-Lahti University of Technology LUT, Lahti, Finland of robots (Mukherjee 2020) along with doubts about robots' technological readiness and the lack of concrete usage scenarios in everyday care practice (Maibaum et al. 2021). In other words, economic pressures motivate the interest in using robotics in the welfare service sector, but the situation regarding the actual use of robots is often described as dynamic due to attitudinal and other constraints (e.g., Pekkarinen et al. 2020b). McGrath and Astell (2017) showed that technology acquisition and use are influenced by positive attitudes (e.g., toward the possibilities of maintaining independence and safety), but also by negative attitudes caused by fear and uncertainty.

Human-robot interaction (HRI) is an intriguing field of study, especially in the context of welfare services. In addition to studying the interaction between individuals and robots in actual encounters and sense making in particular contexts, the study of human-robot interaction includes the broader social context as a necessary component of the successful implementation of robots in society (Šabanović and Chang 2016). Thus, the general attitudes of different stakeholders toward robots can also be considered part of human-robot interactions.

In welfare services, the stakeholder network around robots includes many types of stakeholders (see Hennala 
et al. 2017; Pekkarinen et al. 2020a; Lanne et al. 2020) who represent different interests and fields of expertise and who contribute to value creation in the network (see De Vasconcelos Gomes et al. 2018). To mention a few, the network may include companies that manufacture robots, companies that sell robots, researchers in various fields who develop robots and determine their abilities, people responsible for the acquisition of robots, care services administrators and managers, and care workers. Legislation also plays a role in relation to robots, for example, by controlling the funding for acquisition, determining the responsibilities of service providers who use robots, and regulating health technologies. These stakeholders in the network are hereafter called decision-makers. They can be roughly divided into two groups: service actors and research and development (R\&D) actors (Pekkarinen et al. 2020a). While this network may seem very heterogeneous, it is important to understand that developing robots involves not just technology, but also understanding the needs of users and the potential uses for robots (Whelan et al. 2018) as well as determining effective ways to integrate robots into services (Pekkarinen et al. 2020b), which all require decision-making at different levels.

The attitudes and acceptance of decision-makers toward the use of robots in welfare services have not been widely studied. Interest in robots exists at the grassroots level, but procurement decisions are often made by management, and expectations about suitable applications may vary (Niemelä et al. 2016). Decision-makers are frequently the "gatekeepers" who are responsible for the acquisition of new technological solutions by welfare services and for introducing robots to their users (for example, care workers). Thus, decision-makers play an essential role in robot acceptance among care professionals. Therefore, this study focuses on decision-makers' attitudes toward the use of robots in welfare services and the reasons behind their opinions; specifically, the study compares the views of service actors with those of R\&D actors by investigating (1) their knowledge about robots and (2) their attitude toward the use of robots in welfare services.

This study focuses, in particular, on the use of robots in the care of the elderly. The number of applications and systems in this field is growing all the time, encompassing various tasks, some of which are related directly to care, such as rehabilitation or providing safety at home, while others are related more indirectly to care, consisting of supportive tasks such as cleaning and transportation (Niemelä et al. 2021). The need to provide high-quality care for the growing aging population is of societal and strategic importance. Therefore, research and public discussions on the possibilities of care robots often target care for elderly people. This is the main focus of our study as well, although we touch on other user groups to some extent.

\section{Background}

\subsection{General attitudes toward robots}

Traditionally, robots have been used in industry to assist the human workforce by performing repetitive and dull tasks (Sharkey 2008). For example, robots function well in manufacturing lines where the same task must be performed repeatedly throughout the day (Lopes et al. 2017). Currently, a wide variety of robots are used in addition to those used in industry. Robots can be divided into two categories-industrial robots and service robots [International Federation of Robotics (IFR) 2012]. Robots have also become available for private consumers, for example, robot vacuum cleaners (Forlizzi and DiSalvo 2006).

While the purposes of industrial robots are evident, the uses of service robots, to which category care robots belong (see Okamura et al. 2010), are less clearly defined. The International Organization for Standardization (ISO) defines a service robot as a robot "that performs useful tasks for humans or equipment excluding industrial automation applications" (ISO 8373 2012). Service robots can be defined as those used by service providers or individual consumers to serve people by performing various tasks, for example, vacuum cleaning. Wu et al. (2012) divide service robots into three categories: (1) monitoring robots (to help observe behavior and health), (2) assistive robots (to provide support to the individual and/or their caregiver in daily tasks), and (3) socially assistive robots (to provide companionship). Examples of these robots are telepresence robots (e.g., Double and Giraff), medicine-dispensing robots (e.g., Evondos), robotic walking aids (e.g., Lea), robotic spoons (e.g., Gyenno), exoskeletons for rehabilitation of the patient (e.g., Indego) or for supporting the care worker (e.g., Laevo, Auxivo), transportation robots for delivering meals and medicine (e.g., TUG), and social robots for therapy, entertainment, and communication (e.g., Paro, JustoCat, Zora, Pepper) (Niemelä et al. 2021; Pirhonen et al. 2019). This development from industrial robots to service robots has brought robots closer to people, with the development of robots that are able to assist people in a variety of tasks, such as indoor transportation (Severinson-Eklund et al. 2003; Summerfield et al. 2011).

Attitudes toward robots have been investigated in many service contexts, for example, at home (de Graaf et al. 2019), in elder-care facilities (Melkas et al. 2020; Tuisku et al. 2019), at school (Fridin and Belokopytov 2014), and for shopping (Doering et al. 2015). These studies have often concentrated on the acceptance of one particular robot. The question of acceptance becomes more abstract when dealing with a general level of acceptance-when the study participants' perceptions cannot be tied to a known robot. 
Interestingly, the Europe-wide Eurobarometer surveys (European Commission 2012, 2015) have shown that attitudes toward robots in general are favorable, with $70 \%$ of European respondents expressing a positive attitude toward robots. Finland was found to be the fourth most positive country in Europe in relation to the use of robots, with an $85 \%$ acceptance rate; only Sweden, Denmark, and the Netherlands reported higher acceptance rates. Turja and Oksanen (2019) further investigated Eurobarometer data further from the perspective of robot acceptance in the workplace in general. They found that acceptance of robots as assistants at work depends on the individual's experience, which means that acceptance is more related to the individual's own principles than to the European country in which they live. A recent study by Latikka et al. (2021) concerning working life noted that the participants' attitudes were more positive toward robots as pieces of equipment that are semi-autonomous than toward robots that functioned as autonomous co-workers in the workplace context. This is because the latter may evoke connotations of humans being replaced with robots at work, whereas equipment is more likely to support or complement human work.

The development of the appearance and gestures of robots has mainly concentrated on how robots can be made to act similarly to humans (e.g., Ghazali et al. 2018) or to look like humans (e.g., Walters et al. 2008), although a robot's appearance depends on the particular tasks it was designed to perform. While these are important aspects of human-robot interaction (HRI), it is equally important to understand how people utilize robots in their daily lives and what new possibilities are arising due to interaction with robots. Human-robot interaction is thus not only about the adaptation to and adoption of robots, but also about developing a richer sociotechnical imagination to enable designers to create robots that better fit into particular social contexts (Šabanović and Chang 2016; see also Nickelsen 2018). The departure point for this study is the need for a broad societal understanding of human-robot interaction.

\subsection{Attitudes and acceptance toward care robots}

Studies focusing on participants' experiences and attitudes toward care robots available for utilization in welfare services (Bedaf et al. 2015) include, for example, the therapy seal robot Paro (Wada and Shibata 2007), the socially assistive humanoid robot Zora (Melkas et al. 2020; Tuisku et al. 2019), telepresence robots (Cesta et al. 2016; Koceski and Koceska 2016), and exoskeletons (Sale et al. 2012). In addition to these physical robots, there exist studies of solutions such as voice assistants and chatbots that can be considered to have a social and communicative function in care (e.g., Lee et al. 2020; Skjuve et al. 2021). Acceptance and ethical issues related to socially interactive and therapeutic robots have been studied by Jenkins and Draper (2015) and by McGlynn et al. (2017). However, different types of robots may trigger different responses in terms of acceptance, depending on the target group (Robinson et al. 2013).

Concerning public opinion about care robots, while the Eurobarometer data showed favorable attitudes toward robots in general, using robots specifically in health care was seen negatively. Only $22 \%$ of the general public in Europe accepted the use of robots in health care, with an $18 \%$ acceptance rate in Finland. Literature reviews have also been conducted on the acceptance of robots in various occupational fields (e.g., Savela et al. 2017), and while the results show that attitudes toward robots are positive in many fields of work (e.g., education, business, and industry), in the case of care work, attitudes are more negative. These results are mainly explained by the fact that people consider it inhumane for a robot to take care of a person.

The general public's attitudes toward the use of robots in the care of older people were examined in a media analysis that showed that opinions were mostly negative (Tuisku et al. 2019). It was found that the general public's main concern was that robots would replace human-to-human contact and care. However, based on these results, it was obvious that the general public did not have sufficient knowledge about the use of robots in welfare services. For the general public, media coverage may provide the only information they receive regarding the use of care robots.

Broadbent et al. (2010) investigated general perceptions relating to the use of robots in welfare services. Interestingly, the participants saw many benefits and applications for health-care robots, including performing simple medical procedures and providing physical assistance. However, some participants were concerned about reliability, safety, and the loss of personal care. The researchers concluded that perceptions about the use of robots were influenced by the participants' prior exposure to robots in literature or in entertainment media. Previous research has shown that exposure to robots positively affected attitudes toward them (Broadbent et al. 2010; Melkas et al. 2020), although other studies have obtained contradictory results (Kristoffersson et al. 2011).

In addition to focusing on public opinion, prior research on the acceptance of robots in welfare services has focused on the attitudes of actual users, that is, older people and care workers (Broadbent et al. 2012; Coco et al. 2018; Melkas et al. 2020; Turja et al. 2018). Older people interact with a robot in the course of receiving services from it, while care workers are often the ones who control the robot. The results concerning the attitudes of actual users-older people and their caregivers-indicated that when people had more knowledge about robots, were shown a robot, or were able to use one, their attitudes toward robots became more positive (e.g., 
Johansson-Pajala et al., 2019). Some negative connotations seem to be attached to the idea of care robots, along with an ambiguity in terminology, which may lead to misunderstandings or 'colored' (distorted) information (Pekkarinen et al. 2020a, b). Papadopoulos et al. (2018) reported that health-care workers have mixed views on the use of robots in care settings, and few health-care professionals had used or even seen a robot. A lack of knowledge creates false impressions concerning robots' capabilities and risks (Johansson-Pajala et al. 2020). Providing hands-on experience and promoting increased awareness and education about what care robots can do are necessary to move away from preconceptions based on fiction and imaginary images of robots (Frennert et al. 2021).

Attitudes toward care robots have also been studied through surveys. Turja et al. (2018) investigated the attitudes of Finnish health-care workers toward the use of robots in welfare services and discovered that the views of the healthcare workers were generally negative. However, they considered a robot acceptable for doing certain work tasks, such as heavy lifting. It seems that care workers have reservations about the use of robots in welfare services. On the other hand, Melkas et al. (2020) found that the attitudes of care workers changed when they were able to interact with a robot and witness the positive attitudes of older people. Niemelä et al. (2016) noted in their study that care workers had negative prejudices toward the use of social robots in care, but valued them for their positive social and emotional impact on older residents.

While many of the experiences reported with care robots have been positive (see Beeuwkes Buntin et al. 2011; Andtfolk et al. 2021), certain concerns persist regarding the use of robots in welfare services. Welfare services are traditionally seen as a field in which only humans can perform (Parks 2010; Sparrow and Sparrow 2006). Sharkey and Sharkey (2012) list six concerns regarding the use of robots in elderly care, including (1) a potential reduction in the amount of human contact, (2) an increased feeling of objectification and loss of control, (3) loss of privacy, (4) loss of personal liberty, (5) deception and infantilization, and (6) unclear circumstances under which older people should be allowed to control a robot. The principle fear in utilizing robots in welfare services is the loss of human contact (Sharkey and Sharkey 2010). This fear is expressed by both care personnel who may not have had any experience using a robot with older people and by the general public (Tuisku et al. 2019). However, as many studies show, social robots are not meant to substitute for care workers, but rather to complement them (Pfadenhauer and Dukat 2015), and in fact, additional caregivers may be needed when utilizing a robot with elderly clients (Melkas et al. 2020). In recent years, this fear has characterized the discussion around the utilization of robots.
In the few studies focusing on the views of decision-makers, decision-makers have been shown to have more positive attitudes toward care robots than ordinary employees. For example, Tuisku et al. (2019) found that managers who had been actively involved in the acquisition of a care robot for elderly care saw it as a positive tool. Beedholm et al. (2015) investigated the attitudes of different stakeholders (management, nursing staff, and older people) regarding the acquisition of a robot bath for a nursing home in Denmark. Their interviews revealed that attitudes were highly dependent on the respondent's role. The managers who were responsible for acquiring the robot bath showed the most positive attitude. A study by Niemelä et al. (2016) showed that managers were interested in acquiring a lifting robot, while the caregivers were distrustful and preferred a therapy robot seal. Thus, acceptance may also depend on the robot in question, for example, its appearance and usability (Pfadenhauer and Dukat 2015; Johansson-Pajala et al. 2020).

Gallego et al. (2008) identified the importance of decision-makers' roles in acquiring new health-care technologies. Their study showed that decision-makers, in this case, senior health service managers, nurse managers, and senior medical clinicians, were responsible for the acquisition of new health-care technologies and played an active role in acquiring such solutions. This study revealed that while the managers had to adhere to constraints imposed at a higher level, such as funding issues, they were still in a position to make decisions regarding the kind of technology to be purchased. Thus, people at the level of management and policymaking play a considerable role in the initial introduction of technologies in the care sector, and this is why their motivation and attitudes need to be studied. In addition, they play an important role in the broader stakeholder network.

\section{Methods}

\subsection{Survey}

An online survey was conducted in the spring of 2017 among stakeholder networks (see Pekkarinen et al. 2019) of decision-makers in Finland. The respondents were selected from the identified decision-makers in the field of care robotics, including the service actors responsible for acquiring robots in welfare services (e.g., managers within municipalities and hospital districts) and the research and development actors (i.e., members of parliament and representatives of ministries, businesses in the field of robotics, associations, and research institutes) whose tasks are related to development work in the field of care robotics. A careful screening process was conducted to identify relevant decision-makers (i.e., judgment sampling was utilized) (Marshall 1996). To be more specific, in this case, judgment sampling means that 
our screening was based on the notion of health care as a sociotechnical system (Pekkarinen and Melkas 2019, based on Geels 2002) consisting of the industry, infrastructure, and service structures producing health-care products and services, as well as the products (derived from both high and low technology) and services themselves. The sociotechnical system also consists of policies and people's preferences related to the products and services they use and consume, as well as the response of the market and the public sector to those wishes and requirements (Geels 2002). On the basis of these elements of the sociotechnical system, we identified the stakeholders to include in the study.

Our screening process is also in line with the views of Camarinha-Matos et al. (2015), who noted that ambient assisted-living (AAL) ecosystems possess different value systems, namely, a business-oriented value system and a social-oriented value system, and "in this sense, an AAL ecosystem represents a form of hybrid value chain which combines and leverages the strengths of business and social actors, which although driven by different value systems, share a common goal of providing better care and assistance services and create opportunities for social innovation" (Camarinha-Matos et al. 2015, p. 618).

In Finland, where the present study was conducted, welfare services (including both social and health-care services) are organized by the public sector (i.e., municipals and hospital districts), and they provide comprehensive social and health care for all citizens. For the municipalities and hospital districts, the survey was sent to the registry offices with a letter requesting that the survey invitations be forwarded to the relevant people, such as directors of elder-care facilities, directors of health care or social services and similar people, and the members of municipal councils. ${ }^{1}$ The questions were originally in Finnish, but have been translated into English for this paper. The study followed the ethical principles outlined in the Declaration of Helsinki of 1975, as revised in 2000 and 2008.

In the survey, care robots were defined for the respondents as follows: "Different types of care robots are used to support an older person's daily life. The tasks that care robots can do include, but are not limited to, monitoring vital functions, providing a flexible remote connection with a relative or caregiver, and offering companionship to older people. Care robots can be of different shapes and sizes, depending on the care robot's tasks, and not all care robots are humanlike." Welfare services were defined as "various types of

\footnotetext{
$\overline{1}$ In Finland, members of parliament and municipal councils are elected; anyone over age 18 who is a citizen of Finland (or the municipality) can run for a seat, whatever their social status or full-time occupation.
}

public/private/third sector social and health services as well as health and welfare promotion in general."

The survey, developed by the authors, consists of 45 questions and includes the following elements: background information, general questions about robotics and robotics issues in welfare services, and questions relating to care robots. In this paper, we will focus on analyzing responses to nine questions related to attitudes about and acceptance of robots; these questions are provided in Sect. 3.3.

\subsection{Respondents}

A total of 176 persons (128 females, 47 males, 1 unreported) responded to all questions and were included in this study. The respondents were divided into two groups: service actors $(n=104)$ and research and development (R\&D) actors $(n=72)$. The service actors included persons currently working in health care or elderly care services in municipalities, as well as municipal-level decision-makers. They had received the survey through Finnish municipalities or hospital districts. They included health care managers, elderly care managers, service managers, project managers, administrative coordinators, directors of medical services, and managing nurses. These people and their organizations were considered to represent the potential users of service robots, that is, the user side in the stakeholder network around robots. They have more hands-on expertise in welfare services than the R\&D actors and act at a more local level than the R\&D actors.

The R\&D actors were national-level actors and consisted of members of parliament along with representatives of ministries, enterprises in the field of robotics, associations, and research institutes. The $\mathrm{R} \& \mathrm{D}$ actors represented a wide range of professions, including members of parliament, CEOs, executive managers, research managers, other managers, entrepreneurs, technology consultants, and researchers. While the service actors represent the user side, the R\&D actors can be considered to represent the producer side of the stakeholder network as producers of technology, knowledge, or policies related to service robots. That is, they have less practical expertise related to welfare services, but they are interested or involved in welfare services through the development of policies and technologies or by having conducted research related to the field. More details are provided below in Table 1.

\subsection{Data analysis}

In this paper, we focus on analyzing the responses to nine questions related to attitudes about and acceptance of robots (see Table 2 for details).

Quantitative data were first expressed as mean values or percentages of responses. The data were analyzed using a 
Table 1 Background information about the respondents

\begin{tabular}{lcc}
\hline & Service actors & R\&D actors \\
\hline Gender & 84 & 44 \\
Female & 20 & 27 \\
Male & & \\
Age division & 0 & 0 \\
Under 25 & 3 & 7 \\
$26-35$ & 19 & 8 \\
$36-45$ & 25 & 33 \\
$46-55$ & 44 & 19 \\
$56-65$ & 13 & 5 \\
Over 65 & & \\
Educational background & 3 & 1 \\
Comprehensive school & 6 & 0 \\
Vocational school & 1 & 2 \\
Secondary school graduate & 22 & 9 \\
Bachelor's degree & 59 & 39 \\
Master's degree & 8 & 19 \\
Postgraduate degree (PhD or & & 0 \\
equivalent) & 7 & \\
Other & &
\end{tabular}

pairwise $t$ test to determine the differences between the two user groups - service actors and R\&D actors.

Qualitative data from the responses to questions for which additional information was asked were analyzed using qualitative content analysis (Mayring 2000). The data were first examined many times to fully comprehend the content and then categorized based on the identified themes.

\section{Results}

The results are presented question by question. In cases the question type included an open-ended, qualitative question, the results are presented after the quantitative results.

\subsection{In what context have you heard about the use of robots in welfare services?}

In this question, the respondents were allowed to choose as many options as they wished. On average, the service actors selected 3.99 options, and the R\&D actors selected 5.85 options. Figure 1 shows the mean responses + standard error of the means (SEMs) for each option. Table 3 shows the results of the pairwise comparisons. In case the response was 'other,' the respondents were able clarify their response but, for this question, no clarifications were given.

\subsection{How interested are you in the future of welfare services?}

In this question, the respondents were able to select only one answer. Figure 2 shows a breakdown of the responses. Pairwise $t$ tests were not statistically significant, indicating that the two response groups were equally interested in the future of welfare services.

\subsection{How interested are you in the development of technology?}

In this question, the respondents were able to select only one answer. Figure 3 shows the breakdown of the responses. Pairwise $t$ tests showed that the R\&D actors were more

Table 2 The questions analyzed in this article

\begin{tabular}{|c|c|c|c|}
\hline$\#$ & Questions & $\begin{array}{l}\text { Question type } \\
\text { (i.e., quantitative } \\
\text { data) }\end{array}$ & Clarifications (i.e., qualitative data) \\
\hline 1 & $\begin{array}{l}\text { In what context have you heard about the use of robots in } \\
\text { welfare services? }\end{array}$ & Multiple choice & Only if the response was 'other' \\
\hline 2 & How interested are you in the future of welfare services? & Forced choice & \\
\hline 3 & How interested are you in the development of technology? & Forced choice & - \\
\hline 4 & Have you used a robot(s)? If yes, what kind(s) of robot(s)? & Forced choice & If yes, what kind(s) of $\operatorname{robot}(\mathrm{s}) ?$ \\
\hline 5 & I feel that my knowledge of robotics is. & Forced choice & - \\
\hline 6 & $\begin{array}{l}\text { In general, do you have a positive or negative perception } \\
\text { of the use of robots in welfare services? }\end{array}$ & Forced choice & - \\
\hline 7 & $\begin{array}{l}\text { Has your attitude toward care robots changed within the } \\
\text { past few years? }\end{array}$ & Forced choice & $\begin{array}{l}\text { The respondents were invited to explain the reasons for their } \\
\text { changed attitude regarding the use of care robots }\end{array}$ \\
\hline 8 & $\begin{array}{l}\text { Would you accept being assisted by a robot or that a robot } \\
\text { could be part of your care? }\end{array}$ & Forced choice & $\begin{array}{l}\text { Those who respondent maybe or no were asked to clarify } \\
\text { their response }\end{array}$ \\
\hline 9 & $\begin{array}{l}\text { Would you accept the following groups of people being } \\
\text { assisted by a robot or that a robot could be part of their } \\
\text { care? }\end{array}$ & Multiple choice & $\begin{array}{l}\text { For the selected response option, the respondents were } \\
\text { asked what the robot could do for that particular user } \\
\text { group }\end{array}$ \\
\hline
\end{tabular}




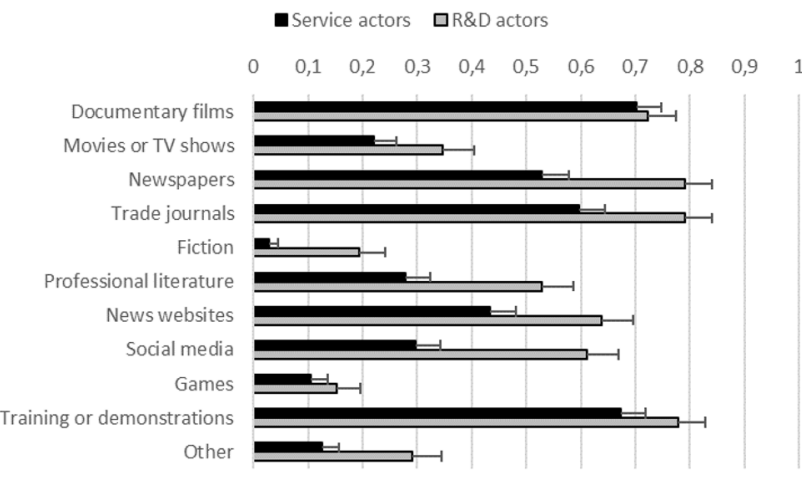

Fig. 1 A breakdown of the responses that indicates where the respondents had heard about the use of robots in welfare services

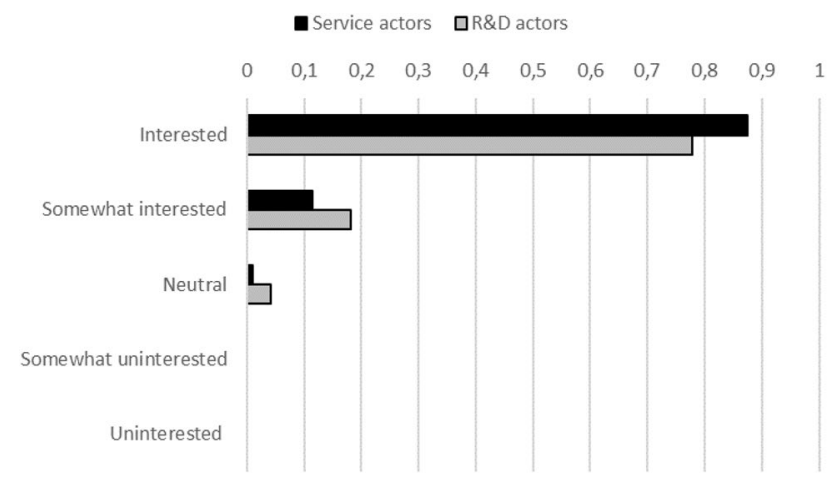

Fig. 2 Level of interest in the future of welfare services

interested in technology development than were the service actors; $t(174)=2.66, p<0.01$.

\subsection{Have you ever used a robot(s)?}

In this question, the respondents were able to select only one answer: 'yes' or 'no.' If the response was 'yes,' the respondents were invited to clarify their answer. The breakdown of responses is shown in Fig. 4. Pairwise $t$ tests

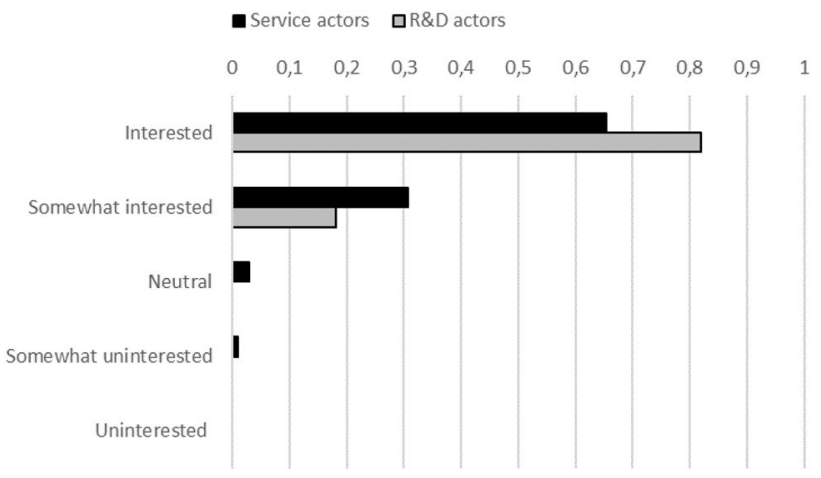

Fig. 3 Level of interest in the development of technology

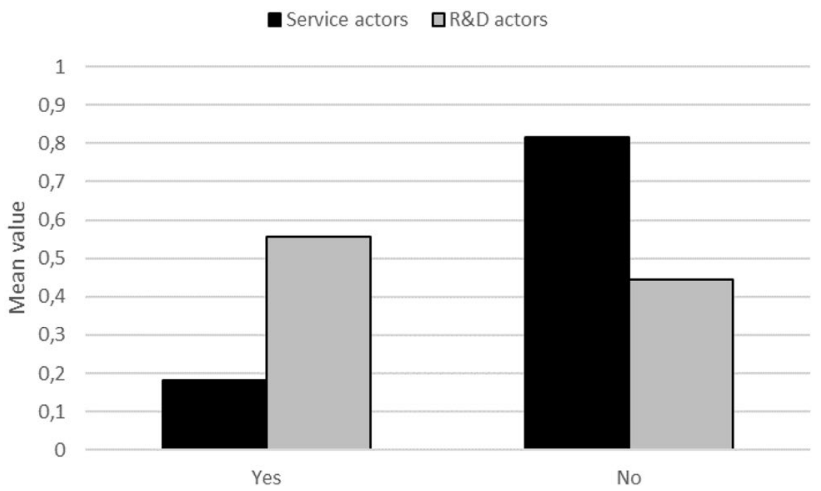

Fig. 4 A breakdown of the responses on the use of robots

showed that the R\&D actors had used significantly more robots than had service actors; $t(174)=5.56, p<0.001$.

While the R\&D actors reported having used robots more than the service actors did, the types of robots used did not differ between the user groups. The respondents reported having used the care robot Zora, NAO, the seal robot Paro, Just-O-Cat, the walking aid Lea, the remote robot Double, remote-controlled drones, software robots, industrial robots, delivery robots, robot vacuum cleaners,

Table 3 Pairwise comparisons

\begin{tabular}{lll}
\hline Factor & Group & $t$ test \\
\hline Documentary films & Service actors $=$ R\&D actors & $\mathrm{ns}$ \\
Movies or TV shows & Service actors $=$ R\&D actors & $\mathrm{ns}$ \\
Newspapers & Service actors $<$ R\&D actors & $t(174)=3.68, p<0.001$ \\
Trade journals & Service actors $<$ R\&D actors & $t(174)=2.76, p<0.01$ \\
Fiction & Service actors $<$ R\&D actors & $t(174)=3.78, p<0.01$ \\
Professional literature & Service actors $<$ R\&D actors & $t(174)=3.43, p<0.01$ \\
News websites & Service actors $<$ R\&D actors & $t(174)=2.73, p<0.01$ \\
Social media & Service actors $<$ R\&D actors & $\mathrm{t}(174)=4.32, \mathrm{p}<0.001$ \\
Games & Service actors $=\mathrm{R} \& D$ actors & $\mathrm{ns}$ \\
Training or demonstrations & Service actors $=\mathrm{R} \& D$ actors & $\mathrm{ns}$ \\
Other & Service actors $<$ R\&D actors & $t(174)=2.79, p<0.01$ \\
\hline
\end{tabular}




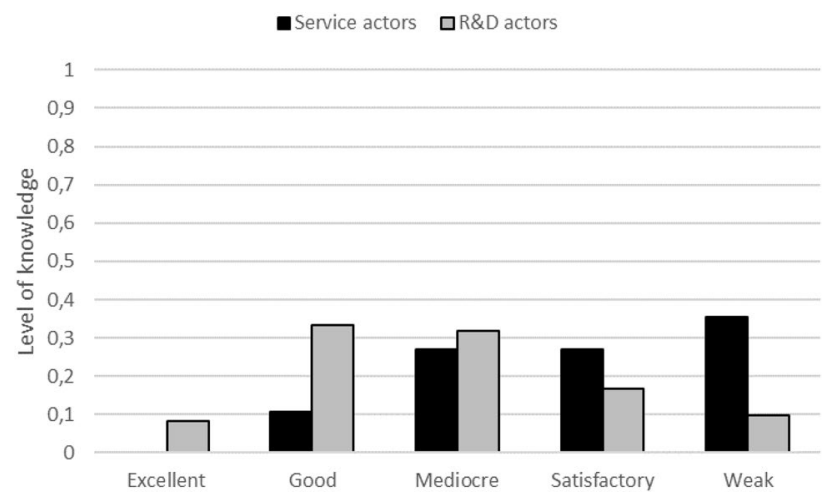

Fig. 5 Level of knowledge about the use of robots

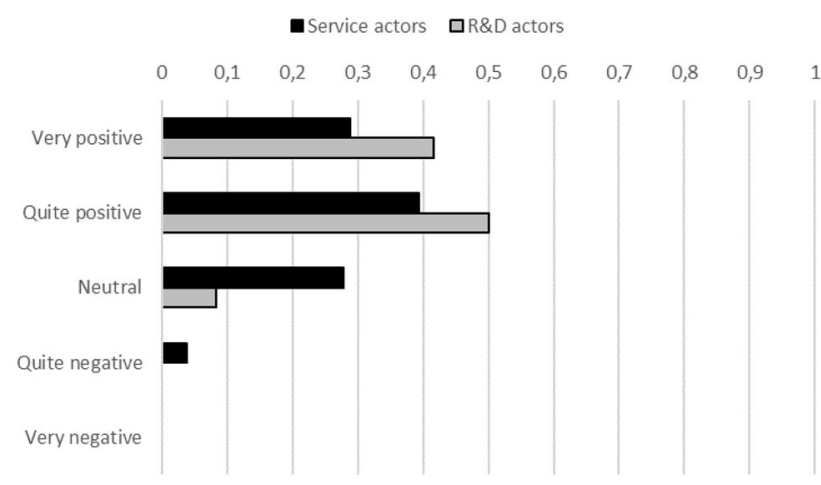

Fig. 6 A breakdown of the responses related to attitude toward the use of robots in welfare services

and robot lawnmowers. Based on these responses, it was evident that the respondents had wide experience with a range of robots, but that not all the robots they had used were related to welfare services.

\subsection{I feel that my knowledge of robotics is:}

In this question, the respondents were able to select only one answer. Figure 5 shows a breakdown of the responses related to the respondents' knowledge of robotics. The pairwise $t$ test showed that the R\&D actors had a better knowledge of robotics than the service actors; $t(174)=6.25, p<0.001$.

\subsection{In general, do you have a positive or negative perception about the use of robots in welfare services?}

In this question, the respondents were able to select only one answer. Figure 6 shows a breakdown of the respondents' responses. Pairwise $t$ tests showed that the R\&D actors had a more positive view of the use of robots in welfare services than the service actors; $t(174)=3.40, p<0.01$.

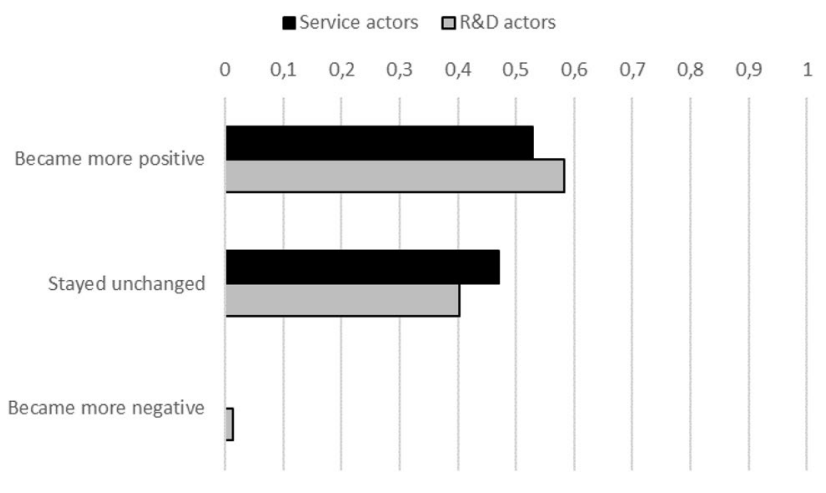

Fig. 7 Responses related to change in attitude in recent years

\subsection{Has your attitude toward care robots changed within the past few years?}

In this question, the respondents were able to select only one answer. The respondents were also invited to explain the reasons for their changed attitude regarding the use of care robots. Figure 7 shows a breakdown of the responses. Pairwise $t$ tests were not statistically significant, indicating that the participants in the two groups had similar views on their change in attitude.

The results are reported as a whole because no statistically significant differences were found between the respondent groups. The reason most often mentioned for a change toward having a more positive attitude was the respondent's increased knowledge of and experience with robots. The respondents also mentioned that they understood that robots would be in use in the future, and this made them willing to learn more about them, which in turn, had affected their attitude. They had also seen that robots would not be replacing humans in their work tasks; rather, they would provide help to humans. Furthermore, they mentioned that robots had been more widely introduced, and this had allowed the respondents to see them 'live,' which had a significant influence on their change in attitude.

For those whose attitude remained unchanged, this was largely because their attitude was already positive. This might have been because these respondents had worked with robots before, either in a robot manufacturing company or in a company that sold robots. One respondent explained that they had always been positively oriented toward new things and that the use of robots in welfare services was no exception. Unfortunately, no reasons were given to explain attitudes that became more negative. Very likely, as suggested in a study by Naneva et al. (2020), increasingly negative attitudes are related to the growing anxiety that the use of robotics would lead to a significant loss of human jobs. 


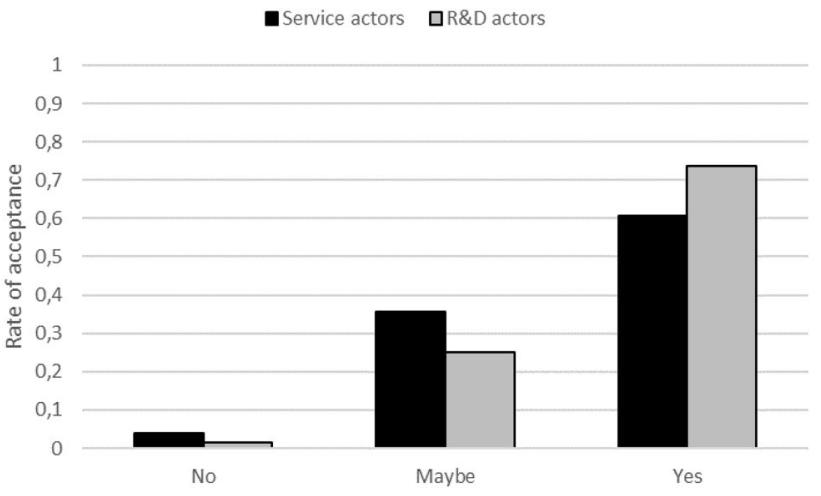

Fig. 8 The rate of acceptance of robots as part of the respondents' own care

\subsection{Would you accept being assisted by a robot or that a robot could be part of your care?}

In this question, the respondents were able to select only one answer. The respondents were also invited to explain the reasons for their acceptance. Figure 8 shows the breakdown of the responses. The pairwise comparisons were not statistically significant, indicating that the two response groups had similar views on accepting robots as part of their care. While the pairwise comparisons were not statistically significant, they indicated that the R\&D actors were more willing than the service actors to accept robots as part of their own care; $t(174)=1.88, p=0.061$.

The respondents who said they would accept a robot assisting them or being part of their care were not asked for their reasons, but those responding maybe or no were asked for clarification. As no statistically significant difference was found between the user groups, the results are reported as a whole.

Among the maybe responses, the robot would be accepted as a helper or as a tool to assist the human caregiver with, for example, cleaning, cooking, and lifting, so the human caregiver would have more time to perform actual care activities. The robot was also seen as a potential companion who could discuss things, read the news, and so on. It was also mentioned that while the robot could assist in care, it could not replace the human touch and social contact between humans. Those giving a no response explained that a robot cannot replace a human, and they were afraid that social contact would suffer.

\subsection{Would you accept that the following groups of people could be assisted by a robot or that a robot could be part of their care?}

In this question, the respondents were able to select multiple answers. On average, the service actors selected 3.21 and the R\&D actors selected 3.72 of the five possible responses. For

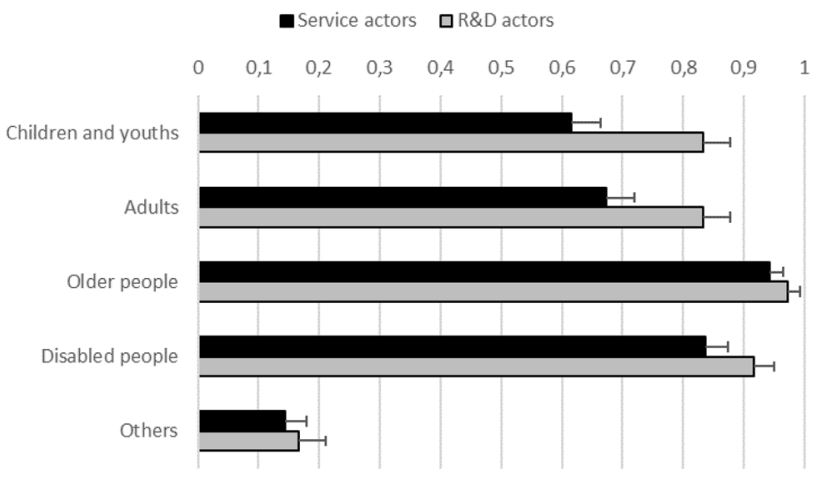

Fig. 9 The rate of acceptance of robots taking care of various groups of people

Table 4 Pairwise comparisons

\begin{tabular}{lll}
\hline Factor & Group & $t$ test \\
\hline Children and youths & $\begin{array}{l}\text { Service actors }<\text { R\&D } \\
\text { actors }\end{array}$ & $t(174)=3.18, p<0.01$ \\
Adults & $\begin{array}{l}\text { Service actors }<\text { R\&D } \\
\text { actors }\end{array}$ & $t(174)=3.18, p<0.05$ \\
Older people & $\begin{array}{l}\text { Service actors = R\&D } \\
\text { actors }\end{array}$ & ns \\
Disabled people & $\begin{array}{l}\text { Service actors = R\&D } \\
\text { actors }\end{array}$ & ns \\
Others & $\begin{array}{l}\text { Service actors = R\&D } \\
\text { actors }\end{array}$ & ns \\
\hline
\end{tabular}

each option, the respondents also provided their ideas about what the care robot could do for that particular user group. Figure 9 shows the mean values + SEMs, and Table 4 shows the results of the pairwise comparisons.

For the response 'children and youths,' the open-ended responses given by the two groups were similar. The respondents in both groups suggested that a robot could, for example, teach language skills, mathematics, reading, gymnastics, or motor skills. They also suggested that a robot could act as a group leader or a source of information for a child (e.g., your mother is running late or your mother will be home soon) or to help the child keep in touch with relatives (e.g., as a device to call a grandmother). However, the service actors suggested more uses for robots in monitoring health issues than the R\&D actors did.

For the response 'adults,' both response groups suggested that a robot could help with everyday chores, such as doing the laundry, carrying heavy objects, and cleaning. They also suggested that a robot could aid in health-related tasks, such as (overall) monitoring, checking the pulse, reminding someone to take medicine, and dispensing medication. The robot could also act as a walking aid. Approximately, 50\% of those who gave an open-ended response to this question suggested that the robot could help with everyday chores, 
and $50 \%$ suggested health-related matters. Interestingly, on this question, the service actors gave more responses relating to companionship than did the R\&D actors.

For the response 'older people,' the tasks that the respondents suggested for robots were similar to those suggested for adults; in addition, they suggested that the robot could give reminders, for example, about a person's daily schedule. The robot could also provide different kinds of entertainment for older people, discuss things with them, read novels or the news to them, and provide general companionship. The two response groups did not differ in their responses.

For the response 'disabled people,' the tasks that the respondents suggested a robot could do were similar to those mentioned above. The only addition was that a robot could assist this group in moving around or could act as a personal assistant. The two response groups did not differ in their responses.

For the response 'others,' only a few respondents suggested additional user groups. One suggested that a robot could help immigrants learn the language skills that they needed in a new country. Another suggested that a robot could work with animals or drive a car. The two response groups did not differ in their responses.

To summarize, the respondents' suggestions about what robots can do for the different user groups were not directly linked to care and care robots. However, the suggestions can be linked to care as they concern improving the quality of life of robot users by offering them different types of services and recreational activities.

\section{Discussion}

Regarding the respondents' knowledge about care robots, the results revealed that the respondents had many sources of information regarding the use of robots in welfare services. Based on the results, it is evident that the R\&D actors had significantly more sources of information than the service actors. The most frequent source of information given was newspapers and/or trade journals, probably since the use of robots in welfare services is a 'hot topic' in the media, and thus, many newspaper articles have tackled the topic (Horowitz 2016; Tuisku et al. 2019). In addition, training and demonstrations played a key role as information sources for the professional community.

The results showed that more than $50 \%$ of the R\&D actors had used robots, while only $20 \%$ of the service actors had. The robots the respondents have used varied from robot vacuum cleaners to socially assistive robots. Still, the respondents evaluated their knowledge of robotics as being on a somewhat mediocre level, although the R\&D actors had a more positive view of their knowledge than the service actors did. In our study, knowledge was a self-reported perception, indicating that the respondents felt that they did not have much knowledge about robots. This was interesting considering that the participants had actually gathered quite a lot of knowledge about robots based on their responses to the question, "In what context(s) have you heard about the use of robots in welfare services?", but perhaps they did not consider "having heard about robots" as knowledge. Earlier studies showed that when people think about robots in general, they often think about Terminator-type robots (Olson and Maio 2003), and thus, knowledge about robots might be scarce and colored. On the other hand, it has also been noted that science fiction may also have a positive impact in paving the way for the acceptance of service robots (Weiss and Speil 2021).

While attitudes toward robots have been found by other studies to be quite negative (e.g., Kristoffersson et al. 2011), our results show that the respondents had a generally positive attitude. When discussing the use of robots specifically in care, our results showed that the R\&D actors had a more positive view of the use of robots in care than the service actors had. A very high percentage of respondents expressed a willingness to accept a robot as part of their own care, and the attitude of the R\&D actors was more positive than that of the service actors. The R\&D actors had more knowledge about and experience with robots than did the service actors. Nomura et al. (2006) showed that individuals' experiences with real robots influenced the relationship between people's negative attitudes and their behavior toward robots; that is, if a person had interacted with a real robot, their attitude would be slightly more positive. The same was also noted by Broadbent et al. (2010) and Johansson-Pajala et al. (2019), who noted that having more knowledge about robots from literature or media had a positive effect on attitudes. Our results support these findings. Social media were also found to affect attitudes, and media exposure played an explanatory role in the acceptance of robots in the care of various groups of people.

It is probable that the positive attitude of the $R \& D$ actors compared to the service actors is related to their reported knowledge level, but it could also be related to other factors, such as the R\&D actors' political and/or economic viewpoints as compared to those of the service actors. While the more positive attitude and greater amount of knowledge about robotics of the $\mathrm{R} \& \mathrm{D}$ actors represents an opportunity to keep robotic development work active and innovative, the challenge for implementation and decision-making is the more negative attitude and smaller amount of knowledge of the service actors. Their smaller amount of knowledge and fewer sources of information, which are connected with more negative attitudes, are likely to affect their motivations when making decisions related to the implementation of care robots. The open-ended responses in the survey 
showed that the reasons for skeptical or negative attitudes lie in the respondents' fear of losing the human touch and social contact, and that robots would be better accepted in assistive tasks such as cleaning, cooking, and lifting. Thus, more effort should be put into providing knowledge regarding human-robot interaction in the context of welfare services, that is, the actual tasks and roles of robots and the division of work between humans and robots. In this regard, to gain a better balance between research and development work and the implementation of robotics in welfare services, it is evident that service actors, in particular, need more knowledge about robotics.

Although our results are clear, this study has some limitations. For example, the respondents did not have a specific robot to which they could connect their attitudes and acceptance. Many previous studies have introduced a specific robot to participants, and this is bound to have an impact on the participants' opinions (e.g., Koceski and Koceska 2016; Melkas et al. 2020; Broadbent et al. 2010). On the other hand, as exposure to robots is likely to create more positive attitudes, investigating the general attitudes of respondents without focusing on a specific robot is more likely to reveal differences. However, in the future, we aim to perform the same survey with people who have used robots regularly; the results would be invaluable in understanding the attitudes of society as a whole.

Decision-makers as network actors play a key role when new types of robots are introduced into welfare services as they are responsible for the acquisition of new technology (Gallego et al., 2008; Pekkarinen et al. 2020a). The contribution of the present study is to highlight the views of those people who are or will be in charge of the acquisition of technological devices for welfare services. As noted by Konttila et al. (2019), "The successful implementation of new technology requires organizational and collegial support." Knowing more about the attitudes of different stakeholders is thus related to the implementation of care robots in practice. If some groups of stakeholders are more negative than others, it is important to understand the reasons behind this. For successful implementation, it is crucial to make the opinions of different stakeholders visible to provide a systemic view of care robot implementation. The systemic view also provides an opportunity to exploit the potential of the structural holes of different stakeholder networks, which is essential to understanding innovation policy practices concerning the use of care robots in society (Parjanen et al. 2021). The digitalization of services requires people in the care sector to acquire at least some understanding of new technological solutions to keep up with career demands, as these careers show great potential for opportunities to get to know care robots (see, for example, Konttila et al. 2019).

Knowledge and attitudes are strongly interrelated; therefore, more attention should be paid to the knowledge about and attitudes toward care robots of the service actors who are closer to daily care and thus to practical decision-making related to the acquisition of technology. The differences in attitudes between R\&D actors and service actors may lead to a situation in which robot-related research and development is boosted and enhanced (by R\&D actors), but the actual implementing actors (service actors) do not understand why. This may lead to problems in the implementation of care robots in welfare services. Thus, the attitudes of both service actors (the user side) and R\&D actors (the producer side) need to be made visible to ensure that robots can be widely implemented in welfare services. Knowledge about robots is clearly one of the explanations for the differences in the attitudes of these two groups. Further research is needed to investigate the reasons behind the differences in the attitudes of R\&D actors and service actors toward care robots.

\section{Conclusion}

This study investigated the attitudes of decision-makers toward the use of care robots in welfare services. It is important to gain a better understanding of the views of the decision-makers who are or will be in charge of the acquisition of technological devices for welfare services and who often play the role of "gatekeepers" in acquisitions. The results of this study showed that the R\&D actors had more overall knowledge of the use of robots than the service actors. The results also showed that, all in all, the attitude toward care robots was quite positive, but there were differences between the $R \& D$ actors and the service actors, and the $R \& D$ actors had a more positive view toward the use of robots in care than the service actors. The differences in attitude between the R\&D actors and the service actors, without an understanding of the reasons for these differences, might lead to a situation where robot-related research and development are enhanced, but problems persist in implementing the use of robots in welfare services. The differing amount of knowledge about robotics between R\&D actors and service actors seems to be one of the explanations for their different attitudes; thus, to facilitate the implementation of robotics in welfare services, service actors decision-makers, in particular, need to have more knowledge about robotics.

Author contributions The authors confirm that the manuscript has been read and approved by all the named authors and that there are no other people that satisfied the criteria for authorship but are not listed. We further confirm that the order of authors listed in the manuscript has been approved by all of us. Author contributions are as follows: OT: contributed to study design, data collection, data analysis and manuscript preparation. SP: contributed to study design, data collection and manuscript preparation. LH: contributed to study design, data collection and manuscript preparation. HM: contributed to study design, data collection and manuscript preparation. 
Funding Open Access funding provided by LUT University (previously Lappeenranta University of Technology (LUT)). This research was supported by the Strategic Research Council at the Academy of Finland [project name: Robots and the Future of Welfare Services (ROSE), decision numbers: 292980, 314180] and the LUT Research Platform on Smart Services for Digitalisation (DIGI-USER).

Availability of data and material The data are stored on the university server (not publicly available). The metadata are publicly available in etsin.fairdata.fi.

Code availability Not applicable.

\section{Declarations}

Conflict of interest The authors report no conflict of interest.

Open Access This article is licensed under a Creative Commons Attribution 4.0 International License, which permits use, sharing, adaptation, distribution and reproduction in any medium or format, as long as you give appropriate credit to the original author(s) and the source, provide a link to the Creative Commons licence, and indicate if changes were made. The images or other third party material in this article are included in the article's Creative Commons licence, unless indicated otherwise in a credit line to the material. If material is not included in the article's Creative Commons licence and your intended use is not permitted by statutory regulation or exceeds the permitted use, you will need to obtain permission directly from the copyright holder. To view a copy of this licence, visit http://creativecommons.org/licenses/by/4.0/.

\section{References}

Andtfolk M, Nyholm L, Eide H, Rauhala A, Fagerström L (2021) Attitudes toward the use of humanoid robots in healthcarea cross-sectional study. AI \& Soc. https://doi.org/10.1007/ s00146-021-01271-4

Bedaf S, Gelderblom GJ, de Witte L (2015) Overview and categorization of robots supporting independent living of elderly people: what activities do they support and how far have they developed? Assist Technol 27(2):88-100. https://doi.org/10.1080/10400435. 2014.978916

Beedholm K, Frederiksen K, Skovsgaard Frederiksen A-M, Lomborg K (2015) Attitudes to a robot bathtub in Danish elder care: a hermeneutic interview study. Nurs Health Sci 17:280-286. https:// doi.org/10.1111/nhs.12184

Beeuwkes Buntin M, Burke MF, Hoaglin MC, Blumenthal D (2011) The benefits of health information technology: a review of the recent literature shows predominantly positive results. Health Aff 30(3):464-471. https://doi.org/10.1377/hlthaff.2011.0178

Broadbent E, Kuo IH, Lee YI, Rabindran J, Kerse N, Stafford R, MacDonald BA (2010) Attitudes and reactions to a healthcare robot. Telemed e-Health 16(5):608-613. https://doi.org/10.1089/tmj. 2009.0171

Broadbent E, Tamagawa R, Patience A, Knock B, Kerse N, Day K, MacDonald BA (2012) Attitudes towards health-care robots in a retirement village. Austral J Ageing 31(2):15-120. https://doi.org/ 10.1111/j.1741-6612.2011.00551.x

Camarinha-Matos LM, Rosas J, Oliveira AI, Ferrada F (2015) Care services ecosystem for ambient assisted living. Enterp Inform Syst 9(5-6):607-633
Cesta A, Cortellessa G, Orlandini A, Tiberio L (2016) Long-term evaluation of a telepresence robot for the elderly: methodology and ecological case study. Int J Soc Robot 8(3):421-441. https:// doi.org/10.1007/s12369-016-0337-z

Coco K, Kangasniemi M, Rantanen T (2018) Care personnel's attitudes and fears toward care robots in elderly care: a comparison of data from the care personnel in Finland and Japan. J Nurs Scholarsh 50(6):634-644. https://doi.org/10.1111/jnu.12435

de Graaf MMA, Allouch SB, van Dijk JAGM (2019) Why would I use this in my home? A model of domestic social robot acceptance. Hum Comput Interact 34(2):115-173. https://doi.org/10.1080/ 07370024.2017.1312406

De Vasconcelos Gomes LA, Figueiredo Facin AL, Salerno MS, Ikenami RK (2018) Unpacking the innovation ecosystem construct: evolution, gaps and trends. Technol Forecast Soc Change 136:30-48. https://doi.org/10.1016/j.techfore.2016.11.009

Doering N, Poeschl S, Gross HM, Bley A, Martin C, Boehme H-J (2015) User-centred design and evaluation of a mobile shopping robot. Int J Soc Robot 7(2):203-225. https://doi.org/10.1007/ s12369-014-0257-8

European Commission (2012) Special Eurobarometer 382: Public Attitudes towards Robots. Technical Report, https://ab.gov.tr/files/ ardb/evt/Public_attitudes_toward_robots_2012.pdf accessed on 14 Jun 2021

European Commission (2015) Special Eurobarometer 427: Autonomous systems. Technical Report, available at: http://ec.europa. eu/commfrontoffice/publicopinion/archives/ebs/ebs_427_en.pdf accessed on 30 May 2020

Forlizzi J, DiSalvo C (2006) Service robots in the domestic environment: a study of the Roomba vacuum in the home. In: Proceedings of the 1st ACM SIGCHI/SIGART conference on Human-robot interaction (HRI '06): 258-265. https://doi.org/10.1145/1121241. 1121286

Frennert S, Aminoff H, Östlund B (2021) Technological frames and care robots in eldercare. Int J Soc Robot 13:311-325. https://doi. org/10.1007/s12369-020-00641-0

Fridin M, Belokopytov M (2014) Acceptance of socially assistive humanoid robot by preschool and elementary school teachers. Comput Hum Behav 33(4):23-31. https://doi.org/10.1016/j.chb. 2013.12.016

Gallego G, Fowler S, van Gool K (2008) Decision makers' perceptions of health technology decision making and priority setting at the institutional level. Aust Health Rev 32:520-527. https://doi.org/ 10.1071/AH080520

Geels FW (2002) Technological transitions as evolutionary reconfiguration processes: a multi-level perspective and a case-study. Res Policy 31(8/9):1257-1274. https://doi.org/10.1016/S00487333(02)00062-8

Ghazali AS, Ham J, Barakova EI, Markopoulos P (2018) Effects of robot facial characteristics and gender in persuasive human-robot interaction. Front Robot AI 73:1-16. https://doi.org/10.3389/frobt. 2018.00073

Hennala L, Koistinen P, Kyrki V, Kämäräinen JK, Laitinen A, Lanne M, Lehtinen H, Leminen S, Melkas H, Niemelä M, Parviainen J, Pekkarinen S, Pieters R, Pirhonen J, Ruohomäki I, Särkikoski T, Tuisku O, Tuominen K, Turja T, van Aerschot L (2017) Robotics in care services: a Finnish Roadmap, available at: http://rosep roject.aalto.fi/images/publications/Roadmap-final02062017.pdf accessed on 28 Apr 2021

Horowitz MC (2016) Public opinion and the politics of the killer robots debate. Res Polit 2016:1-8. https://doi.org/10.1177/2053168015 627183

International Federation of Robotics (IFR) (2012) World robotics: industrial robots 2012. IFR, Frankfurt 
ISO 8373 (2012) Robots and robotic devices-vocabulary, available at: https://www.iso.org/standard/55890.html accessed on 30 May 2020

Jenkins S, Draper H (2015) Care, monitoring, and companionship: views on care robots from older people and their carers. Int J Soc Robot 7(5):673-683. https://doi.org/10.1007/s12369-015-0322-y

Johansson-Pajala R-M, Thommes K, Hoppe J A, Tuisku O, Hennala L, Pekkarinen S, Melkas H, Gustafsson C (2019) Improved knowledge changes the mindset: older adults' perceptions of care robots. In: Zhou J, Salvendy G (eds) Human aspects of IT for the aged population. Design for the elderly and technology acceptance. HCII 2019. Lecture Notes in Computer Science, vol 11592. Springer, Cham. https://doi.org/10.1007/978-3-030-22012-9_16

Johansson-Pajala R-M, Thommes K, Hoppe JA, Tuisku O, Hennala L, Pekkarinen S, Melkas H, Gustafsson C (2020) Care robot orientation: what, who and how? Potential users' perceptions. Int J Soc Robot 12:1-15

Koceski S, Koceska N (2016) Evaluation of an assistive telepresence robot for elderly healthcare. J Med Syst. https://doi.org/10.1007/ s10916-016-0481-x

Konttila J, Siira H, Kyngäs H, Lahtinen M, Elo S, Kääriäinen M, Kaakinen P, Oikarinen A, Yamakawa M, Fukui S, Utsumi M, Higami Y, Higuchi A, Mikkonen K (2019) Healthcare professionals' competence in digitalisation: a systematic review. J Clin Nurs 28(5-6):745-761. https://doi.org/10.1111/jocn.14710

Kristoffersson A, Coradeschi S, Loutfi A, Severinson-Eklundh K (2011) An exploratory study of health professionals' attitudes about robotic telepresence technology. J Technol Hum Serv 29(4):263-283. https://doi.org/10.1080/15228835.2011.639509

Lanne M, Tuisku O, Melkas H, Niemelä M (2020) My business or not? The perspective of technology companies on shifting towards care robotics. Eur Plan Stud 28(2):296-318. https://doi.org/10.1080/ 09654313.2019 .1652249

Latikka R, Savela N, Koivula A, Oksanen A (2021) Attitudes toward robots as equipment and coworkers and the impact of robot autonomy level. Int J Soc Robot 13:1747-1759. https://doi.org/10.1007/ s12369-020-00743-9

Lee K, Lee KY, Sheehan L (2020) Hey Alexa! a magic spell of social glue? Sharing a smart voice assistant speaker and its impact on users' perception of group harmony. Inf Syst Front 22:563-583. https://doi.org/10.1007/s10796-019-09975-1

Lopes TC, Sikora CGS, Molina RG, Schibelbain D, Rodrigues LCA, Magatão L (2017) Balancing a robotic spot welding manufacturing line: an industrial case study. Eur J Oper Res 263(3):10331048. https://doi.org/10.1016/j.ejor.2017.06.001

Maibaum A, Bischof A, Hergesell J, Lipp B (2021) A critique of robotics in health care. AI \& Soc. https://doi.org/10.1007/ s00146-021-01206-z

Marshall MN (1996) Sampling for qualitative research. Fam Pract 13:522-525

Mayring P (2000) Qualitative content analysis. Forum: qualitative social research, 1(2), article 20

McGlynn SA, Kemple S, Mitzner TL, King C-HA, Rogers WA (2017) Understanding the potential of PARO for healthy older adults. Int J Hum Comput Stud 100:33-47

McGrath C, Astell A (2017) The benefits and barriers to technology acquisition: understanding the decision-making processes of older adults with age-related vision loss (ARVL). Br J Occup Ther 80(2):123-131. https://doi.org/10.1177/0308022616667959

Melkas H, Hennala L, Pekkarinen S, Kyrki V (2020) Impacts of robot implementation on care personnel and clients in elderly-care institutions. Int J Med Inform 134:104041. https://doi.org/10.1016/j. ijmedinf.2019.104041

Mukherjee S (2020) Emerging frontiers in smart environment and healthcare-a vision. Inf Syst Front 22(1):23-27. https://doi.org/ 10.1007/s10796-019-09965-3
Naneva S, Sarda Gou M, Webb TL, Prescott T (2020) A Systematic review of attitudes, anxiety, acceptance, and trust towards social robots. Int J Soc Robot 12:1179-1201. https://doi.org/10.1007/ s12369-020-00659-4

Nickelsen NCM (2018) Feeding assistive robotics, socio-technological imaginaries, and care: The case of Bestic. REELER Working Paper Series, Aarhus University, Copenhagen, Denmark

Niemelä M, Määttä H, Ylikauppila M (2016) Expectations and experiences of adopting robots in elderly care in Finland: perspectives of caregivers and decision-makers. In: 4th International Conference on Serviceology, ICServ 2016. Society for Serviceology

Niemelä M, Heikkinen S, Koistinen P, Laakso K, Melkas H, and Kyrki V (eds) (2021) Robots and the Future of Welfare Services-a Finnish Roadmap. Aalto University publication series CROSSOVER, 4/2021. http://urn.fi/URN:ISBN:978-952-64-0323-6

Nomura T, Kanda T, Suzuki T (2006) Experimental investigation into influence of negative attitudes toward robots on human-robot interaction. AI \& Soc 20(2):138-150. https://doi.org/10.1007/ s00146-005-0012-7

Okamura AM, Mataric MJ, Christensen HI (2010) Medical and healthcare robotics. IEEE Robot Autom Mag 17(3):26-37. https://doi. org/10.1109/MRA.2010.937861

Olson JM, Maio GR (2003) Attitudes in social behaviour. Handb Psychol Three 13:299-325

Papadopoulos I, Koulouglioti C, Ali S (2018) Views of nurses and other health and social care workers on the use of assistive humanoid and animal-like robots in health and social care: a scoping review. Contemp Nurse 54(4-5):425-442. https://doi.org/10.1080/ 10376178.2018.1519374

Parjanen S, Hennala L, Pekkarinen S, Melkas H (2021) Knowledge brokerage needs in building care robotics innovation ecosystems and networks. Eur Plan Stud. https://doi.org/10.1080/09654313. 2021.1998386

Park JA (2010) Lifting the burden of women's care work: should robots replace the "human touch"? Hypatia 25(1):100-120. https://doi. org/10.1111/j.1527-2001.2009.01086.x

Pekkarinen S, Melkas, (2019) Welfare state transition in the making: Focus on the niche-regime interaction in Finnish elderly care services. Technol Forecast Soc Change 145:240-253. https://doi.org/ 10.1016/j.techfore.2018.09.015

Pekkarinen S, Tuisku O, Hennala L, Melkas H (2020a) Robotics in Finnish welfare services: dynamics in an emerging innovation ecosystem. Eur Plan Stud 28(8):1513-1533. https://doi.org/10. 1080/09654313.2019.1693980

Pekkarinen S, Hennala L, Tuisku O, Gustafsson C, Johansson-Pajala RM, Thommes K, Hoppe JA, Melkas H (2020b) Embedding care robots into society and practice: socio-technical considerations. Futures 122:102593. https://doi.org/10.1016/j.futures.2020. 102593

Pfadenhauer M, Dukat C (2015) Robot caregiver or robot-supported caregiving? Int J Soc Robot 7(3):393-406

Pirhonen J, Melkas H, Laitinen A, Pekkarinen S (2019) Could robots strengthen the sense of autonomy of older people residing in assisted living facilities?-A future-oriented study. Ethics Inf Technol. https://doi.org/10.1007/s10676-019-09524-z

Robinson H, MacDonald BA, Kerse N, Broadbent E (2013) Suitability of healthcare robots for a dementia unit and suggested improvements. J Am Med Dir Assoc 14(1):34-40

Šabanović S, Chang WL (2016) Socializing robots: constructing robotic sociality in the design and use of the assistive robot PARO. AI \& Soc 31(4):537-551

Sale P, Franceschini M, Waldner A, Hesse S (2012) Use of the robot assisted gait therapy in rehabilitation of patients with stroke and spinal cord injury. Eur J Phys Rehabil Med 48(1):111-121 
Savela N, Turja T, Oksanen A (2017) Social acceptance of robots in different occupational fields: a systematic literature review. Int J Soc Robot 10(4):493-502. https://doi.org/10.1007/s12369-017-0452-5

Severinson-Eklund K, Green A, Hüttenrauch H (2003) Social and collaborative aspects of interaction with a service robot. Robot Auton Syst 42(3-4):223-234. https://doi.org/10.1016/S0921-8890(02) $00377-9$

Sharkey N (2008) Computer science: the ethical frontiers of robotics. Science 322(5909):1800-1801. https://doi.org/10.1126/science. 1164582

Sharkey N, Sharkey A (2010) The crying shame of robot nannies: an ethical appraisal. Interact Stud 11(2):161-190. https://doi.org/10. 1075/is.11.2.01sha

Sharkey A, Sharkey N (2012) Granny and the robots: ethical issues in robot care for the elderly. Ethics Inf Technol 14(1):27-40. https:// doi.org/10.1007/s10676-010-9234-6

Skjuve M, Følstad A, Fostervold KI, Brandtzaeg PB (2021) My Chatbot Companion-a study of human-chatbot relationships. Int J Hum Comput Stud 149:102601. https://doi.org/10.1016/j.ijhcs. 2021.102601

Sparrow L, Sparrow L (2006) In the hands of machines? the future of aged care. Mind Mach 16(2):141-161. https://doi.org/10.1007/ s11023-006-9030-6

Summerfield MR, Seagull FJ, Neelesh V, Xiao Y (2011) Use of pharmacy delivery robots in intensive care units. Am J Health Syst Pharm 68(1):77-83. https://doi.org/10.2146/ajhp100012

Tuisku O, Pekkarinen S, Hennala L, Melkas H (2019) "Robots do not replace a nurse with a beating heart": the publicity around a robotic innovation in elderly care. Inf Technol People 32(1):4767. https://doi.org/10.1108/ITP-06-2018-0277

Turja T, Oksanen A (2019) Robot acceptance at work: a multilevel analysis based on 27 EU countries. Int J Soc Robot 11(4):679689. https://doi.org/10.1007/s12369-019-00526-x
Turja T, van Aerschot L, Särkikoski T, Oksanen A (2018) Finnish healthcare professionals' attitudes towards robots: reflections on a population sample. Nurs Open 5(3):300-309. https://doi.org/ $10.1002 /$ nop 2.138

Wada K, Shibata T (2007) Living with seal robots-its sociopsychological and physiological influences on the elderly at a care house. IEEE Trans Rob 23(5):972-980. https://doi.org/10.1109/TRO. 2007.906261

Walters ML, Syrdal DS, Dautenhahn K, Te Boekhorst R, Koay KL (2008) Avoiding the uncanny valley: robot appearance, personality and consistency of behaviour in an attention-seeking home scenario for a robot companion. Auton Robot 24(2):159-178. https://doi.org/10.1007/s10514-007-9058-3

Weiss A (2021) Spiel K (2021) Robots beyond science fiction: mutual learning in human-robot interaction on the way to participatory approaches. AI \& Soc. https://doi.org/10.1007/ s00146-021-01209-w

Whelan S, Murphy K, Barrett E, Krusche C, Santorelli A, Casey D (2018) Factors affecting the acceptability of social robots by older adults including people with dementia or cognitive impairment: a literature review. Int J Soc Robot 10(5):643-668. https://doi.org/ 10.1007/s12369-018-0471-x

Wu Y, Fassert C, Rigaud AS (2012) Designing robots for the elderly: appearance issue and beyond. Arch Gerontol Geriatr 54(1):121126. https://doi.org/10.1016/j.archger.2011.02.003

Publisher's Note Springer Nature remains neutral with regard to jurisdictional claims in published maps and institutional affiliations. 